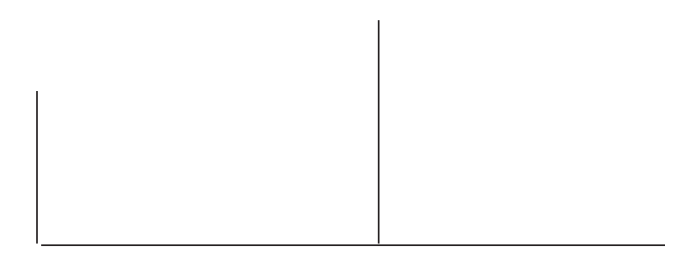

Rev. Latinoam. Psicopat. Fund., X, 2, 274-292

\title{
Crise social extrema, processos identificatórios e resistência psíquica Os Druzos na guerra do Líbano*
}

Jamil Zugueib Neto

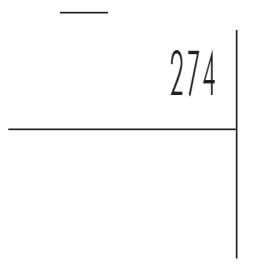

\begin{abstract}
O trabalho se propõe analisar os impactos que uma crise social extrema pode ter sobre a construção identitária e nas condições psíquicas dos cidadãos. Procurou-se identificar quais foram os dinamismos psíquicos e sociais que tiveram relevância para enfrentar o perigo, ultrapassar a crise e, ao final dos combates, nas recomposições de suas vidas. O Líbano foi escolhido, por ter sido cenário de uma longa guerra inter-étnica, onde o povo Druzo esteve no centro das confrontações. Para conhecer esta realidade foram realizadas treze histórias de vida. A análise do material recolhido mostra o papel da memória coletiva e do discurso étnico como propiciadores da coesão grupal. A idealização e as crenças através de suas ideologias, serviram como garantia de sentido na mediação do vivido catastrófico.
\end{abstract}

Palavras-chave: Processos identitários, conflitos étnicos, Líbano, Druzos

* Baseado na tese de doutorado, Identité et crise social. L'influence du bouleversement social sur le processus identitaire et les conditions psychiques des citoyens. Le cas des Druzes dans la guerre du Liban. 2000, Université Toulouse Le Mirail, Toulouse, França. 


\section{Introdução}

A proposta deste trabalho é analisar as condições psíquicas de indivíduos que atravessam um longo período de desorganização social grave. Quisemos saber de seus processos identitários individual e coletivo quando atravessam uma revolução civil, e que logo se transforma na mais violenta das crises sociais: uma guerra etnoconfessional. Procurou-se saber do papel das crenças, da memória coletiva e das ideologias no processo de resistência (resiliência) psíquica durante os conflitos armados e depois de acabada a guerra, no período da reconstrução do país. As pesquisas foram realizadas no Líbano, país que enfrentou entre 1975 e 1991 sangrenta luta fratricida e que é constituído por uma complexa composição de comunidades religiosas e que se imbricam em diferenciados matizes políticos. Esses confrontos foram conseqüências da própria constituição do país, que traz em sua história a animosidade e o conflito intercomunitário desde antes de sua fundação como estado-nação. Assinalamos que este trabalho é fruto de uma pesquisa de campo realizada por meio da observação participante e da extração de histórias de vida com indivíduos da comunidade Druza e que serviram como exemplo para nossos objetivos. A orientação segue as diretivas epistemológicas da psicossociologia, seja a interação entre psicologia social e psicanálise. 


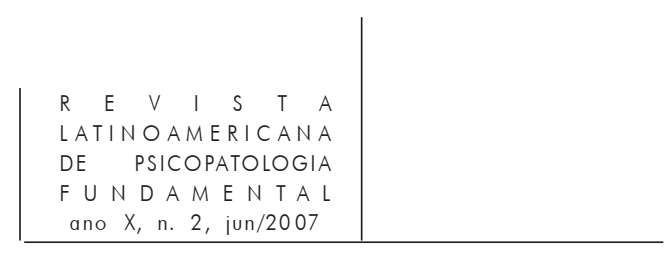

Para entrarmos na questão vamos primeiramente contextualizar, ainda que muito esquematicamente, as relações comunitárias e o conflito armado no país, mas sublinhando que nosso único interesse é o viés dos processos das identidades culturais, remarcando a polarização Druzo-Maronitas que se amarram ao fio da história libanesa e sintetiza como situação extrema, as animadversões comunitárias que se espalham pelo Oriente Médio. Em seguida teceremos algumas considerações sobre as identidades culturais, a relação crise extrema e condições psíquicas para, finalmente, apresentar os nossos resultados.

\section{A crise vivida pelos libaneses}

A associação de guerra civil e guerra confessional constitui uma das mais terríveis catástrofes sociais, pois além da perda de um poder político central, associa-se à visão de um inimigo compacto e indiferenciado que deve ser apagado como a mensagem profética do mal. Além disso, uma guerra interna deixa o meio inapreensível e com fronteiras incertas. Assim, o contexto torna-se incompreensível, surpreendente e fora de controle. A impossibilidade de uma organização cotidiana de vida e de se construir um projeto existencial positivo em médio prazo, associado aos boatos terrificantes de massacres eminentes, deixam a situação fértil para a produção fantasmática de terror, de ódio e propiciador do comportamento pulsional.

Durante a guerra, um terço da população nacional emigrou (um milhão de pessoas) e o restante foi obrigado a participar como ator da grande catástrofe social que se abateu sobre o país. Difícil foi o indivíduo que não tenha se defrontado com situações traumáticas, e que não tenha sido obrigado a mudar de residência segundo os deslocamentos dos confrontos. Tais afrontamentos irão reavivar a memória coletiva, acender velhos ódios comunitários e a sede de extermínio entre eles. O Líbano é constituído por 17 comunidades entre muçulmanos e cristãos, mas são seis as que conduzem o país: muçulmanos: sunitas, xiitas e druzos; cristãos: maronitas, ortodoxos e católicos. Entre o tripé fundador do país, os sunitas, os maronitas e os druzos, estes dois últimos mantém uma relação de oposição que data do século XIX. As batalhas e massacres perpetrados pelos Druzos em 1860 são guardados ainda na memória dos maronitas e teve influência na lógica da guerra contemporânea. Em 1982 estes últimos subiram as montanhas apoiados pelas tropas comandadas, então, pelo general israelense Ariel Charon, com a intenção de expulsá-los do país. No entanto, foram rechaçados pelas milícias druzas, que juntamente com a população civil de cada lugarejo se organizaram em comitês de defesa, inclusive com muitas mulheres armadas comandan- 


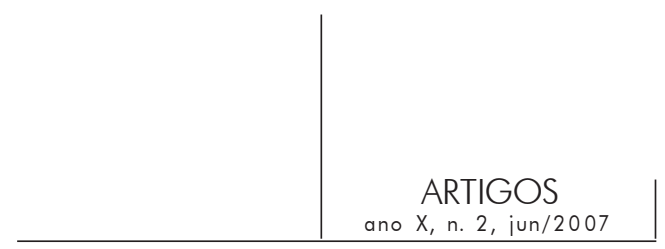

do essas tarefas. E a guerra continuou até 1991 com intervalos de acalmia e com súbitas e imprevisíveis explosões de reinício e massacres.

Alguns traços do contexto político comunitário libanês

Entre as principais comunidades, cada uma delas concebe um Líbano enquanto Estado, e uma história para seu país que diverge da dos outros. O que faz alguns autores (Beydoun, 1984) insistirem que não existe um Líbano, mas diversos segundo suas fontes e tendências políticas. Este fato vai concorrer a diferentes concepções de uma identidade nacional e conseqüentemente um currículo escolar básico. As causas envolvidas nessa complexa guerra se superpõem politicamente e se engatam aos elos da história, da memória e da lenda sobre cada etnia que chegou àquelas montanhas. Rapidamente sublinhamos que os druzos constituem peculiar e temida etnia que carrega um estigma através de sua história, e que muito já se fantasiou sobre suas origens: nem árabes seriam, com costumes bárbaros e devassos. Seriam os adoradores do mítico bezerro de ouro, e até muito recentemente era crendice que possuiriam rabo (?). Há um adágio popular no Líbano que diz: "Não se pode confiar em um Druzo, pois nunca se sabe o que se passa em sua cabeça”. Eles surgiram no Cairo no século XI como dissidência dos ismael itas, estes já um ramo alternativo do xiísmo. A seita não segue todos os preceitos do Islã (e por isso são tratados com desconfiança e reprovação) e que por perseguições religiosas, refugiaram-se naquele tempo nas montanhas do Líbano. Eles representam aproximadamente $6 \%$ da população do país, mas pelo seu peso histórico e temerária tradição guerreira, conquistaram uma posição de respeito na balança política nacional. Eles se consideram quase imbatíveis na guerra, acreditam na transmutação da alma, prezam muito a tradição beduína, a palavra empenhada, a hospitalidade, a vida montanhesa e a elevação espiritual em detrimento dos bens materiais.

Outro pólo do atrito, os cristãos maronitas seguidores do asceta Maroum, que viveu no vale do Orontes no ano 400, permanecem no poder presidencial como funesto legado deixado pelos colonizadores. A França seus protetores, lhes defenderam em 1860 dos muitos massacres que houveram naquele século, e por sua imposição em tratados posteriores estabeleceram que o presidente da república deveria ser sempre um cristão, o vice um sunita e o presidente da câmara um xiita (e esta foi a causa política da revolução quando tentou-se reverter esta ordem no início da guerra). Os maronitas recusam qualquer identificação cultural com os povos árabes, sublinhando que teriam uma mentalidade radicalmente diferente, diga-se mais avançada, do que o funcionamento mental dos componen- 


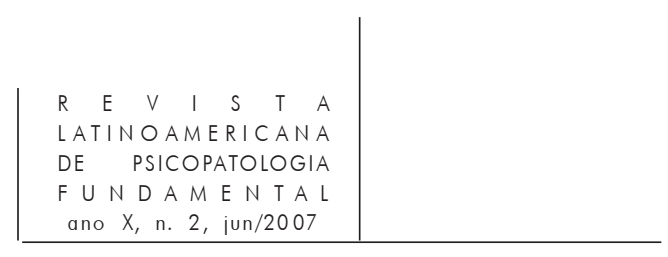

tes da grande Uma (comunidade) árabe. Apesar de no passado ocuparem papel de vanguarda na imprensa e na renovação literária árabe (a Nahda), a partir dos anos sessenta passaram a insistir nas suas raízes fenícias e reivindicarem tradições européias que remontam aos tempos das Cruzadas. Evidentemente que são defensores das políticas ocidentais com relação ao Oriente, e estabeleceram alianças desde o início do conflito libanês com as forças de Israel, que lhes forneceu apoio logístico e material. Possuem, portanto, uma identidade híbrida com a francesa e se representam como ilhados em um mar árabe-muçulmano.

À guisa de informação, as relações druzo-maronitas iniciaram-se no século XVII, quando Fakhr al Din II então no apogeu do emirado druzo naquelas montanhas, incentivou os maronitas a virem habitar o Monte Líbano. As causas do fosso que os separou, culminando em grandes morticínios, remontam ao século XIX (1860), quando o desenvolvimento comercial e populacional dos maronitas ameaçou a sobrevivência econômica druza. O acirramento dos ânimos foram alimentados pelos interesses concorrentes dos colonizadores franceses e ingleses, quando até então as trocas sociais eram satisfatórias.

Grosso modo na guerra civil, alinharam-se representantes e aliados dos três grandes partidos cristãos de direita e pró-ocidentais. Eram liderados principalmente pela comunidade maronita, que defendia um Líbano libanês, ou seja, um Líbano somente para os cristãos. Esta coligação se debateu com os partidos de esquerda (inclusive alguns cristãos) de maioria muçulmana, que defendiam os palestinos e sua causa (na época com suas tropas acantonadas no país) e que se alinhavam pela defesa do "arabismo": por um Líbano multicultural e de raízes árabes.

Estes últimos se uniram em uma ampla coalizão denominada Movimento Nacional e que foi comandada pelo líder da comunidade druza Kamal Joumblat. Assim quis a história, que novamente viesse a baila dois atores, representantes de duas propostas diferentes para o Líbano, e novamente acendesse a chama da centenar e simbiótica ${ }^{1}$ oposição entre Druzos e Maronitas. Sublinhe-se também que nesse pequeno país, colocou-se em ato o viés tenebroso de uma relação Ocidente-Oriente conflitual. Como se ela fosse uma interminável e definitivamente irreconciliável guerra de culturas.

\section{As identidades étnicas}

Antes de tecermos alguns comentários sobre as identidades culturais, queremos destacar esta questão no Líbano.

1. Concepção compartilhada por diversos autores libaneses. 


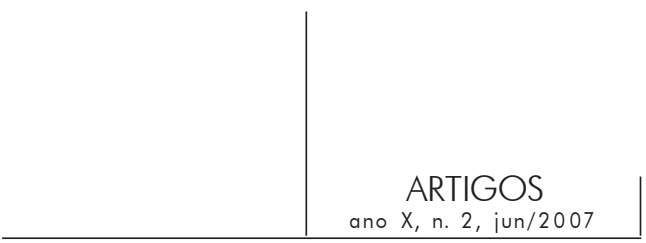

No Oriente Médio as comunidades confessionais ultrapassam as identificações propriamente religiosas. Elas implicam também uma organização social, uma orientação política e uma representação cultural, assim como poderão manter laços de clientelismo com umas, e seguramente uma relação de antagonismo com outras.

$\mathrm{O}$ fato de existirem comunidades religiosas nas montanhas libanesas anteriores à criação de uma entidade nacional comum, conduziu a uma superposição e confusão da história de cada comunidade com a história da entidade nacional, e aí reside o nó conflituoso da questão da identidade nacional e as raízes da violência comunitária. Certas delas, de acordo com seu peso sociopolítico, são levadas pelos interesses de suas elites, a anexar na história nacional mais recente, a história de sua própria comunidade. E assim são criados a partir dos conflitos comunitários de 1840-1860, os diversos mitos e fantasias sobre as origens libanesas. As referências históricas de cada uma e mais alguns dados falseados, observa Corm (1982) levaram à criação de uma "cultura da discórdia", onde certos dados parciais tornam-se verdades absolutas para determinada comunidade e passam a ser apresentadas como características permanentes da vida e do traço libanês. Lembranças que podem despertar a solidariedade podem da mesma maneira reacender o ódio, pois no Líbano "a memória é fator de encerramento comunitário" (Tar Kovacs, 1997, p. 26). Esta relação vai dar margem a uma permanente desconfiança intercomunitária, provocando o alerta e um estado de prontidão para os conflitos que se abrem nos assuntos de estado ou na concorrência para o exercício de qualquer posto-chave na burocracia governamental.

Estes relacionamentos conflituosos exemplificam nossa concepção de que as identidades étnicas sempre se referem a um passado comum e freqüentemente mítico. Esta crença dará uma aura de parentalidade entre seus componentes e funda uma memória coletiva que se encaixará no imaginário grupal. Por sua vez, esta construção promoverá as suas fronteiras simbólicas que abrigam dentro dela a sua especificidade autoproclamada. Esta identificação solidificará as interações entre os semelhantes que se reforçam pelo envolvimento no pensamento social comunitário, como a ideologia e suas crenças. Neste envolvimento se constroem um calendário comum, referências e significações para o grupo. Juntamente com os valores e a normas, eles servem como grades de orientação, culto aos personagens exemplares e regulação dos comportamentos sociais do sujeito. Esta modelagem do comportamento coletivo acompanha a construção progressiva do eu, diga-se, do processo de subjetivação do sujeito que tem seu início na resolução edipiana, e a sua entrada na ordem simbólica. Então concluímos que a identidade coletiva é um desdobramento, uma construção contínua de outra face da identidade individual. 


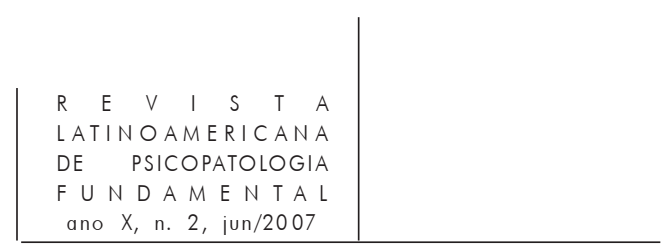

Relações de uma crise social extrema e a resistência psíquica

A queda da mediação simbólica nas relações comunitárias e a irrupção do real do inconsciente do sujeito nas situações de perigo, instigam a representação da pulsão de morte em variados fantasmas de destruição. O medo da perda do controle de si e do meio circundante, marcará a divisão profunda a que o sujeito é submetido. O meio advém inapreensível, o contexto torna-se incompreensível, surpreendente e fora de controle. Boatos e possibilidades de massacres iminentes associados à impossibilidade de uma organização de vida e de um projeto existencial satisfatório a médio prazo, deixam a situação fértil para o comportamento pulsional e a prática da crueldade. Esta ameaça, o pathos libanês, no que ele conteve de sofrimento, paixão e excesso provocavam a perda das orientações cotidianas que se repetiram ao fio de 15 anos, marcará profundamente $\mathrm{o}$ ator libanês, desestabilizando-o subjetivamente.

Um indivíduo que possua boas condições de resistência (resiliência, segundo a nomenclatura dos estudos nesse assunto) psíquica em situações de caos social, será aquele que possui características psicológicas de sobreviver, de resistir e de sobrepujar as condições de vida adversas e que ponham em perigo seu bom desenvolvimento pessoal. Certamente diversos fatores concorrem para tal, situando-se entre a herança genética e as condições ambientais. A interação do indivíduo com fontes de apoio social em situações catastróficas é evidenciada desde as primeiras pesquisas na Segunda Guerra Mundial. O poder benéfico da mediação da entourage familial (uma mãe com bom controle emocional) foi assinalado entre outros por Punamaki (1983 e 1989) e Mahjoub (1989); realizando pesquisas com populações palestinas, residentes no sul do Líbano durante a guerra, evidenciaram o papel positivo na preservação da saúde mental de seus filhos, quando suas mães, não exteriorizando medos extremos, mostravam maior participação social e engajamento nas ações coletivas de seu grupo. A confluência de resultados com outras pesquisas com jovens e crianças israelenses residentes em kibutz nas guerras de 1967 e 1973 (Kaffman, 1983) demonstraram que uma comunidade que entretém fortes laços de relacionamento e de determinação nas atitudes, oferecerá positivamente melhores meios que assegurem um sentimento de defesa e de segurança. No entanto, isso não impediu que houvesse a ocorrência de sintomas como medos noturnos, agressividade e outros problemas comportamentais, mas não se pode caracterizá-los como problemas psiquiátricos mais graves.

Por outro lado, sobre o estado de ânimo individual, pesquisas realizadas no pós-guerra (Karam, 1991) em um bairro de Beirute, mostraram que havia então um estado geral de falta de esperança e uma diminuição do interesse em participar 


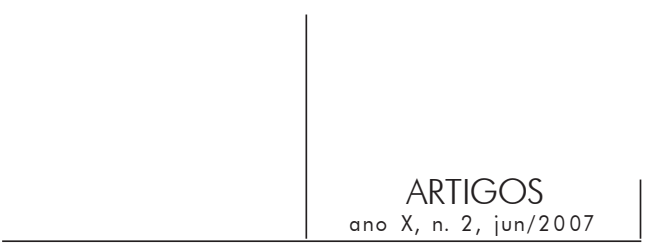

de atividades sociais. Esses sintomas depressivos coexistiam com diversos sintomas arrolados na alínea dos Distúrbios e Stress Pós-Traumáticos (DSM-IV). Eram essas as condições psíquicas que se observavam ainda ao tempo de minha intervenção. Passo agora, então, a relatar a minha experiência.

\section{A pesquisa de campo}

Extraí no pós-guerra (1997), treze histórias de vida de combatentes (sete) e não combatentes (seis) distribuídos proporcionalmente quanto ao sexo e ao estado civil e que contassem em torno de vinte anos, quando do começo dos afrontamentos. Uma primeira questão motivou esta divisão: haveria diferenças significativas entre combatentes e civis nas questões a serem averiguadas?

As entrevistas foram realizadas nas residências e locais de trabalho nas montanhas do Chouf, tradicional região onde habitam os Druzos do Líbano.

O itinerário das questões partiu de uma perspectiva visando o sujeito étnico. Portanto, sublinhou o sujeito em vínculo. E procuraram captar os seus modelos, formas e as significações que faziam sentido para o sujeito. Visou-se, então, as representações que faziam união, projetos e que atuavam nas relações intercomunitárias. Buscamos no discurso étnico: os ícones culturais e suas significações na memória coletiva; os eventos retidos de seu passado e suas relações com o oponente. Observamos as condições psíquicas e os projetos de vida.

A seqüência visou formalizar as experiências dos atores, em função também das futuras análises. Assim dividimos as histórias em três capítulos: 1) infância e adolescência antes e 2) durante a guerra; e 3) a atualidade ao tempo da reconstrução do país.

As linhas que se seguem são resultados da análise de conteúdo do material coletado. Àquela época eram jovens que tentavam compreender o difícil tabuleiro de xadrez que era o Líbano, e a complexidade da conjuntura regional. Muitos deles já tinham anteriormente participado de revoltas urbanas quando houve tentativas de se mudar o currículo escolar da história do Líbano e, segundo eles, mais uma manipulação para a dominação dos partidários de um Líbano só para cristãos. Os "isolacionistas" segundo K. Joumblat, isolar o Líbano como uma particularidade nas vastas terras dos árabes.

Foi assim que nesse clima exaltado cresce, para esses jovens, a figura de seu líder comunitário Kamal Joumblat. Descendente de uma família que há mais de duzentos anos comanda a comunidade, Kamal foi um ativo participante da história recente do país. Odiado por uns, temido por outros, mas respeitado por todas as 


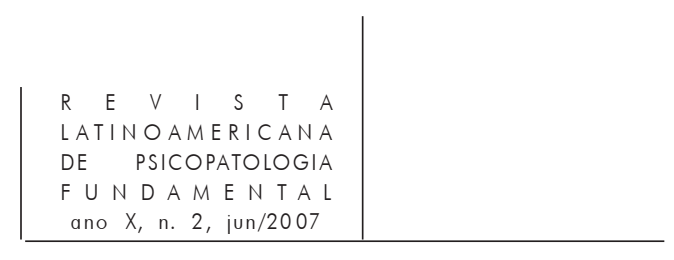

facções, pela sua conduta ética e patriótica nos seus trinta anos de vida como guerreiro e líder político (ministro e deputado eleitos várias vezes). Fundou o Partido Socialista Progressista em 1946 e mantinha várias alianças com líderes internacionais (países não alinhados dos anos 1960 e com Gamal A. Nassar e seu projeto utópico pan-arabista). Seus livros, discursos e artigos em jornais serviram de orientação para esses jovens. Com carisma ele dirigiu a comunidade e era respeitado como um puro representante da alma druza, o último elo da grande cadeia de seus ícones históricos: um yogui praticante do sufismo, homem de cultura e estudioso que trilhou o caminho do tawhid - a trilha para o encontro com a Unidade Primordial. Segundo os depoimentos ele foi a lente da comunidade e seu livro, Pelo Líbano (1978) publicado no começo da guerra, trazia toda a leitura do jogo político envolvido, a interpretação histórica do país, seus complôs e suas relações comunitárias. A obra ficou como seu testamento político, pois Joumblat foi metralhado logo no início da guerra. O livro torna-se paradigma, síntese, chave de resoluções interpretativas, que vai provocar a conjunção de sentido não só para os seus comandados, como para toda a comunidade. Turbinado pelo clima de guerra e envolvido emocionalmente com aqueles que seriam os representantes de sua identidade negativa, ele vai fortalecer o vínculo opositivo e por contraste nesta colusão de contrários; a sua própria identidade é realçada pelo que não seria, apontando no Outro o que este outro ele pensa que é. Ele tece ferozes críticas ao propalado espírito empreendedor libanês e afirma que "esta nossa nação" deveria ser mais do que um conjunto de butiques abertas para o mar. Em seguida o desafio: exalta seus mitos fundadores e o espírito guerreiro de seu povo. Suas falas sublinhavam suas raízes árabes e suas tradições filosóficas, antípodas do pensamento mercenário, capitalista e superficial dos vendidos ao espírito decadente ocidental. Ele acendia nos seus prosélitos, o desejo de esclarecer suas identidades, clarear algo que permanecia obscuro nos seus patrimônios simbólicos: O pensamento e a mística druza dentro do Islã. Buscando suas origens, eles se fortificavam e validavam suas ações.

\section{A identidade druza}

O nó duro da identidade druza repousa nos ensinamentos esotéricos contidos em seus livros sagrados, e que são interditados aos não iniciados (exemplo de seu pensamento: "Não se precisa ir a Meca, o importante é ter a Meca dentro de si"). Há a concepção de uma essência druza que se transmite pela transposição da alma de um druzo que morre a outro que vem a nascer. Esta crença associada à defesa da honra tribal e ao princípio de que a matéria é insignificante em relação ao 


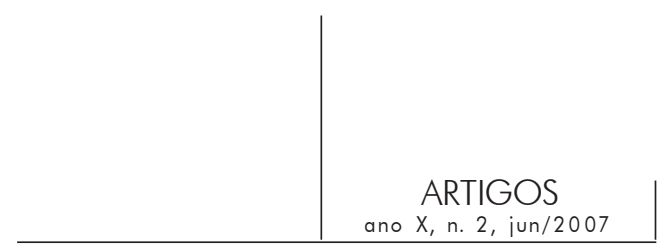

mundo espiritual ("o corpo é uma camisa que se troca"), vai reforçar o seu espírito guerreiro e seu destemor frente à morte. Eles são conscientes do histórico estigma que carregam, no entanto para eles é a honra tribal, a discrição e a conduta ética de cada um, que pode mostrar a dignidade e as suas diferenças. Resumo abaixo algumas características sublinhadas por meus informantes e que tiveram importância como fatores de reforçamento psíquico nos anos de violência. Ser druzo é:

- Ter recebido a alma de outro druzo

- Respeitar a palavra, o seu empenho e a honra

- Ser racional, dominar as emoções e procurar a verdade

- Ter gestos de nobreza, não guardar rancor e ser hospitaleiro

- Dar auxílio a quem necessite sem esperar recompensa

- Ser herdeiro de um passado glorioso e venerar seu território

- Odiar a submissão

- Crer em uma razão superior e única

- Ser interdito de fazer a guerra, salvo em defesa da comunidade

Em suas idealizações de uma meta para um comportamento bem orientado, há a corporificação de três figuras míticas: o guerreiro destemido, o cavaleiro de gesto nobre e o místico da montanha.

\section{A memória coletiva e a mística de um destino epopéico}

Reproduzo o testemunho do Cel. Walid Safi, ${ }^{2}$ comandante de campo de suas milícias, que nos dá um vívido testemunho da pregnância da memória coletiva induzindo o comportamento combativo druzo.

Nossa história mostra que a cada vez que há um conflito no Líbano, nós somos colocados na frente da cena. Os eventos atuais eram a repetição de nossa história, mostravam que a cada 50, 100 anos, somos levados à frente da batalha. Isto mobilizou a organização de nossa defesa, obrigando um rápido restabelecimento psíquico depois da morte de nosso líder e mestre Kamal Joumblat. As lembranças dos afrontamentos deste século (1958 e 1969) nos remetiam aos conflitos de 1840 e 1860 e mais longe ainda na história do principado druzo do Monte Líbano, quando os

2. Cito um recorte das entrevistas dadas pelo ex-comandante de campo das milícias druzas. Observo que depois de eu ter sido aprovado nas entrevistas com as lideranças mais velhas, o jovem coronel foi a pessoa destacada para me conduzir e orientar nos primeiros reconhecimentos de sua comunidade e da relação de seus clãs. Foi ele quem escolheu os combatentes para as entrevistas. 


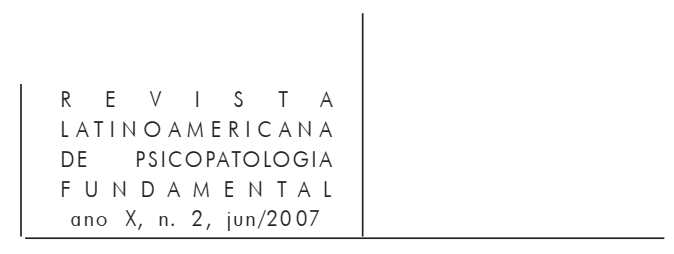

nossos emires dominavam estas montanhas, não se submetendo ao Império Otomano. Nossos ancestrais tiveram sucesso na preservação de nosso território e naquele momento percebíamos que a história se repetia e que estávamos investidos dos mesmos papéis. Nas reuniões noturnas no campo de batalha, falávamos de nosso destino, de nossos valores, de nossa reconhecida coragem guerreira e sabendo que cada Druzo vale cinco ou dez combatentes de outras comunidades. Falávamos de amor e da significação do corpo para um Druzo: com efeito, cremos na reencarnação e a morte não é nada mais que uma troca de corpo. Essas discussões nos davam motivação e coragem para ir ao combate, sem medo da morte. Era necessário defender nossas mulheres e nossa honra. Esta crença era forte e constituiu um motor na luta, mas isso não impedia que nossos pais sentissem medo por seus jovens. Mas era consenso sobre uma designação do destino. Esse sentimento nos uniu (civis e combatentes) e reforçou nossa coesão, cada vila organizou sua defesa e não houve algum comportamento de pânico. Verdadeiramente nos sentíamos uma placa de estanho: "Batia-se de um lado, e ela ressonava do outro".

\section{As quatro faces da identidade druza}

A interpretação que abre e fecha o círculo de apreensão da experiência de nossos atores atravessa sem dúvida o crivo do pesquisador, que conhece as histórias relatadas e as nuanças de suas intenções. Antes de tudo levei em consideração que as imbricações evento-sujeito se oferecem como chaves de compreensão do fio desenvolvimental do sujeito; e que estas auxiliam a clarificar os seus laços simbólicos desenvolvidos com seu meio circundante. Dá-se então a essas conexões, funções "operatórias", servindo elas como matrizes de interpretações para as nossas aproximações. Sublinho esta evidência de antemão, para me servir de um instrumento de auxílio nesta tarefa. Um programa informatizado para organizar os depoimentos segundo critérios estatísticos e semânticos que permitiram organizar as suas diferentes formas de expressão. Trata-se de Alceste ${ }^{3}$ cujo objetivo principal é determinar como são organizados os elementos que constituem um texto e de reduzir o arbitrário da descrição, colocando em evidência suas regularidades e suas simetrias não aparentes.

O instrumento veio possibilitar a distribuição dos discursos em classes segundo uma modelização de leis de distribuição do vocabulário e ao mesmo tempo cruzando unidades do contexto e o vocabulário retido (Reinert, 1990). A hipótese principal do programa considera o vocabulário de um enunciado um

3. Alceste: Analyse Lexicale par Contexte d'un ensemble de segments de texte (Reinert, 1992). 


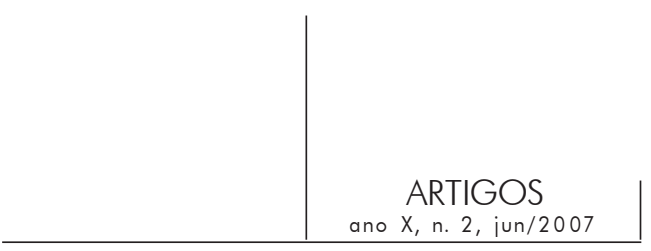

elemento representativo do ponto de vista do sujeito, portanto o léxico reenvia não somente as representações que um sujeito faz de um objeto, mas sua maneira de apreendê-lo em função de sua própria identidade.

Os resultados obtidos por Alceste na análise das 13 histórias permitiu organizar os testemunhos em quatro classes discursivas. Há um discurso de combatente voltado mais para a sociedade (out-groupe) e outro de civis e voltados para a comunidade (observar a figura abaixo). Este resultado mostra antes de tudo a congruência dos relatos, o que remete a um imaginário e uma memória social consistente, presente e bem acordada entre os sujeitos.

Esta arquitetura representa os quatro pólos da identificação druza, quatro correntes de pensamento e maneiras de sentir, ligados por um nó comum, a representação de seu líder. Cada classe vai constituir uma ponte, um ponto de contato com o mundo exterior (out groupe). No plano individual, essas disposições mostram as quatro maneiras de sentir de um mesmo sujeito, que polariza uma entre elas, de acordo com a situação ou o momento histórico de seu percurso vital.

Kamal Joumblat é figura emblemática, representado como porta voz da alma druza. É aquele que se debate na modernidade, sem ter perdido a sua essência. Cada face sublinha uma característica percebida no líder, e revela aí o contorno de seu próprio esquema identificatório.

Faço uma sintética ilustração:

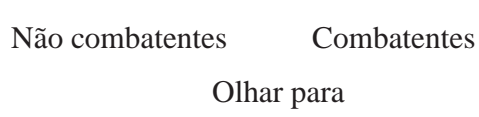

Olhar para

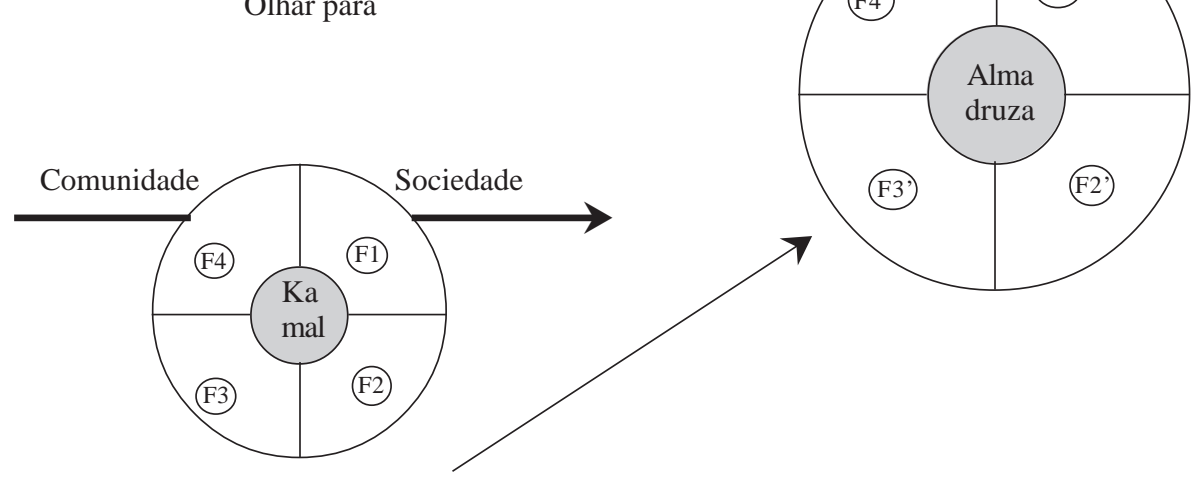

F1 - A identidade guerreira

F1'- O líder é visto como o chefe que reúne a massa em torno de si. Ele foi o comandante contra o esfacelamento do país. 


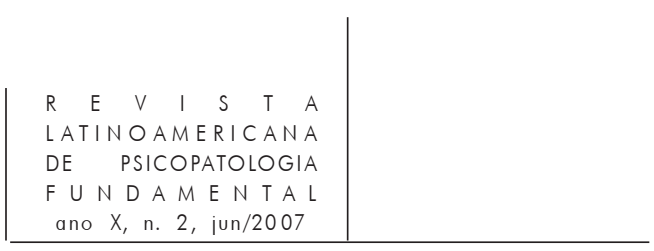

F2 - A identidade sociopolítica

F2' - O líder é visto como um homem de letras, o mestre, a lente. Um político que desenvolveu a ética e a compreensão.

F3 - A identidade humanista religiosa

F3'- O líder é visto como agente de transformação. O sábio, yogui e um "iniciado". Ele soube viver a atualidade sem perder a essência druza.

F4 - A identidade nostálgica-comunitária

F4' - O líder é visto como um político compreensivo, que falou de igualdade, literatura e de cortesia

\section{As condições psíquicas depois da guerra}

Tentarei indicar, entre vários sintomas relatados, a disposição psíquica principal segundo as faces identitárias.

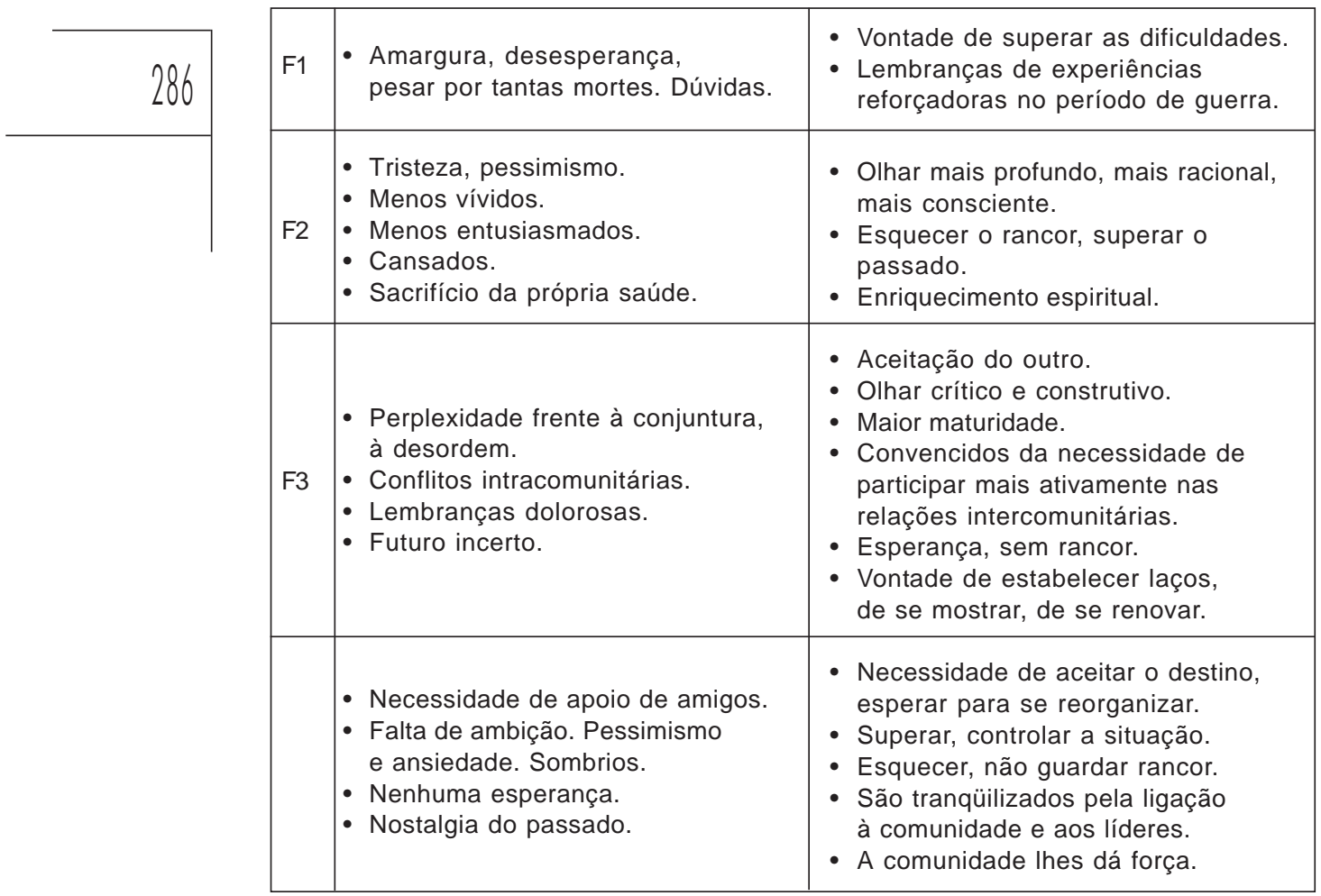




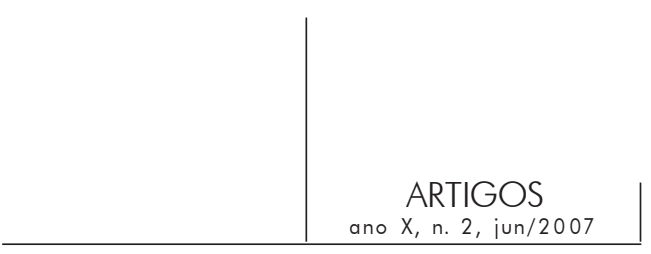

Comentários

Amargura, desesperança, lembranças dolorosas e a visão de um futuro incerto; satisfação e orgulho misturados com dor e tristeza. Nossos sujeitos se dizem tensos com a conjuntura de pós-guerra, preocupados com a participação política e a discriminação que sofre a sua comunidade; na vida privada, sentemse entediados pela monotonia da vida cotidiana. Este sofrimento identitário pode ser diagnosticado, segundo o DSM-IV, no quadro dos Problemas e Stress PósTraumáticos. Assinalo alguns de seus sintomas: sentimento de futuro truncado; lembranças repetitivas; esforços para evitar as atividades e lugares que despertam lembranças traumáticas; sentimento de distanciamento; restrição dos afetos.

Por outro lado, e guardadas as proporções, o druzo nutre ânimo para avançar, refazer alianças, participar da reconstrução do país. Os longos sofrimentos atravessados o faz hoje pensar em um "aprendizado pela amargura e pela dureza da dor”. Mas há, também, um sentimento muito forte de orgulho comunitário e confiança em si, por ter vencido o inimigo, combatido um exército israelense sofisticado e cumprido seus deveres face à sua comunidade, aos palestinos e ao seu país, que acabou não sendo dividido.

A grande catarse experimentada os faz atualmente "sentirem-se em glórias e em repouso" (F2). Há o sentimento de uma renovação identitária: eles se apercebem mais maduros, mais racionais, conscientes de si e da complexidade conjuntural do país. "Aceitam mais o outro" e procuram mais o convívio comunitário para aplacar o cansaço e a nostalgia de uma época perdida, mais segura e amigável do que antes da guerra.

Uma reflexão clínica mais cautelosa nos alerta que as atividades da vida diária podem estar mascarando significações traumáticas mais profundas e que podem aflorar subitamente como sintomas agudos ou disparar comportamentos como formações reativas que podem oscilar entre a depressão e a mania. Essas atividades funcionariam como um tampão que impediria o retorno do recalcado, experiências necessitando elaboração e posterior integração à subjetividade do sujeito. O fato da possibilidade de haver uma irrupção retardada faz com que se tenha cautela quanto a afirmações nos seus desenhos identitários e em suas condições psíquicas para o futuro.

\section{Conclusões}

A crise social condicionou a exacerbação dos mecanismos internos e interacionais dos sujeitos, e exigiu o controle egóico da situação, que se mostrava 


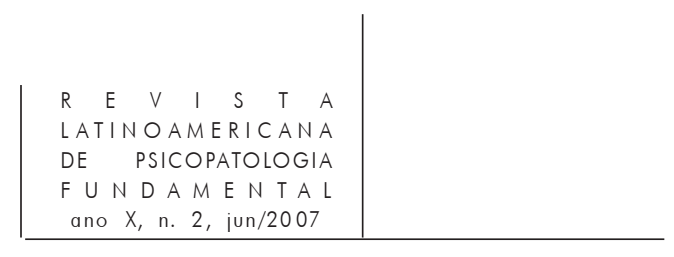

ameaçadora e confusa. O gesto primeiro para se posicionar, achar o seu lugar e rebater a angústia na desorganização, foi inquirir da sua própria identidade, procurando o conhecimento de suas origens e a sua história no contexto libanês.

Kamal, o "venerável mestre", é objeto de um discurso amoroso por parte de todos. Ele ocupa o lugar do Ideal do Eu de cada jovem, um lugar, uma posição a ser atingida: "Ele é amado pelas perfeições pelas quais se aspira ao próprio eu, e que se procura agora, para satisfazer o próprio narcisismo" (Freud, 1921, p. 177).

Em um segundo momento, ameaçador para a unidade comunitária, a morte do mestre eleva ainda mais sua idealização, o transforma em um traço simbólico e acaba desenhando-se mais vívido na consciência de seus liderados. O eu se modifica, operação que concorre para a defesa contra a depressão dos sujeitos e no refortalecimento dos laços grupais.

\section{O ideal-do-eu compartilhado e a resistência étnica}

O projeto grupal solidificado pela mensagem do chefe ordenou o desejo individual para a articulação de uma conexão de sentido intracomunitário. Ele é objeto de "uma relação amorosa" e que tocava no "narcisismo de suas pequenas diferenças". O discurso de Kamal, como paradigma introjetado, ofereceu a organização, a coerência e a discriminação necessária ao Eu de nossos sujeitos, para o controle dos dados confusos da realidade. Assim, ele tem efeitos organizadores do processo primário. A integração desses fatores nas operações do Eu auxiliou-o em suas funções integrativas, críticas e criativas, com relação às exigências do meio. $\mathrm{Na}$ dimensão social as interpretações comuns que o discurso promoveu, reavivou a memória coletiva, reforçaram os laços identitários e acelerou o gerenciamento logístico entre civis e combatentes para enfrentar as situações críticas. Como traço simbólico o chefe reaparece no Eu dos atores e mostra-se através de sua fala, "modificando-o parcialmente segundo a mensagem deste objeto perdido" (Freud, 1921). A significação onipresente do mito coletivo foi de tal monta que suas mensagens acalentaram o amalgamento das relações complementares intragrupo. O Eu e o ideal-do-eu unidos, nas representações do sujeito durante as batalhas entre suas montanhas, deram uma aura de assujeitamento a um destino épico, onde os cavaleiros fizeram face ao inimigo e asseguraram-se contra as forças desagregadoras internas. A leitura daquela situação confirmava sua tradição, legitimava seus atos e reforçava as condições psíquicas na manutenção do equilíbrio interno. Os dispositivos simbólicos canalizaram os desejos individuais, fizeram economia psíquica, evitando a interrogação sobre o valor de seus atos. Desta maneira o laço simbólico funcionou 


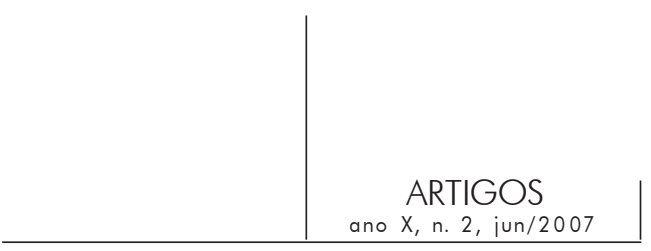

como um pára-raios antitraumático. A ideologia étnica torna-se objeto de adesão idealizada e como cabeça de lança, fundamentará as decisões e rompendo as situações inesperadas. A representação de minoria honorável, iluminada pelos seus mitos fundadores, surgiu imanente nas consciências e irradiou a força de determinação para a defesa comunitária. Ela fundamentou a transgressão social e amparou-os em seus combates temerários, tão exaltados por sua memória coletiva e tão temidos por seus adversários.

Ansart (1977) sublinha que o sistema simbólico não é somente sistema de orientação de ações, mas também elevação das energias coletivas; ele transforma as práticas dispersas em práticas orientadas. Essas são moduladas na utopia grupal, fazendo economia dos desvios e reforçando as alianças em seus momentos críticos.

Mais do que nunca as identificações nestas situações de catástrofe social tiveram um papel assegurador na integridade dos sujeitos. No pensamento de Tap (1981) elas foram:

1) Construtiva: no sentido de oferecer uma representação valorizada de si-mesmo;

2) Defensivas: elas auxiliaram na mitigação da angustia e no desaparecimento do sentimento de impotência;

3) Elas participaram na dinâmica da adaptação, da percepção e de fazer face às pressões exteriores.

Para finalizar, lembremos que a força e os efeitos de um evento só podem ser avaliados quando se conecta com as significações dadas pelo sujeito.

Os eventos são uma realidade tanto concreta como abstrata e que faz referência a um calendário pleno de significações por aquele que participa de uma sociedade. Um evento como dado subjetivo e antropocêntrico será vivido e será integrado em um tempo particular do sujeito. "Um evento só pode ser descrito em relação a um sujeito" (Tatossian, 1989). Eventificando suas ações, o druzo advém ator do grande teatro da guerra, ele dá valor, significa e articula-a à sua história individual. A situação vivida não foi um acidente, ele participou de sua construção, e já havia em sua memória um espaço simbólico que funcionou como amortecedor para acolhê-la e em seguida a enfrentá-la. E assim se construindo, foi na ação que ele achou um sentido. A conexão de suas estruturas inconscientes com as estruturas simbólicas das relações grupais assegurou a alimentação e a economia libidinal junto aos dispositivos ideológicos de seu grupo. O psíquico e o social conectados em alta tensão motorizaram o sujeito, talhando-o na construção de sua história.

Sem dúvida que o caos social potencializando os fantasmas individuais deixará marcas em sua personalidade, mas não podemos prever se eles serão negativos ou se contribuirão para o seu fortalecimento. As cenas traumáticas vão 


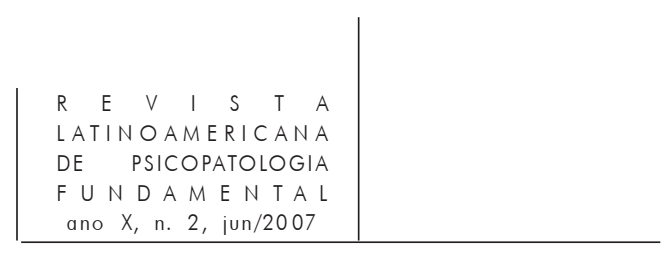

se decompor em fantasmas. Estes fragmentos vão se introduzir nas diversas cadeias associativas, e que serão pouco reconhecíveis para a consciência do sujeito. Eles serão integrados a diversos comportamentos, sintomáticos ou não, nas suas reorganizações identitárias futuras. A participação da reconstrução da sociedade e a retomada de suas vidas, inclui o controle consciente, a sublimação, e os mecanismos de deslocamento que vão concorrer nos remanejamentos psíquicos necessários para a procura de um sentido em suas novas condutas e também auxiliar no recalque de investimentos indesejáveis de antigos objetos. O reforçamento do Eu recebe contribuições também nos projetos comunitários compartilhados no pós-guerra, que auxiliam na canalização das energias libidinais e na procura de novos objetos a serem investidos. A renovação identitária, a partir do exposto, obtém contornos sutis. As marcas impressas se inocularão em outras pregas identitárias e, por condensação e deslocamento, metáforas e metonímias, vão contribuir na configuração de outros desenhos, novas formas de acionar um sentido. A resignação interior e o acolhimento ofertado pela comunidade vai se refletir na confiança em si e no conforto espiritual. "É preciso dar graças de estar como estamos e ter o que temos, pois esperávamos o pior. Os princípios lembrados por Kamal nos dão esperanças" (Khaldoun representante de F4).

Tal desabafo revela um conjunto interior renovado na sua nova forma de o sujeito se contar a própria história, quando os eventos ainda quentes, se transformarão em referências simbólicas de sua própria vida. Momento de transformar a biografia em história.

\section{Referências}

ANSART, Pierre. Ideologies, conflcts, pouvori. Paris: PUF, 1977.

BEyDoun, Ahmad. Identité confessionelle et temps social chez les historiens libanais Contemporains. Beirute: Publicação da Universidade Libanesa, 1984.

Freud, Sigmund (1921). Psychologie des foules et Analise du Moi. Paris: Payout, 1977. Joumblat, Kamal. Pour le Liban. Paris: Stock, 1978.

Kaffman, M. e Elizur, E. Bereavement responses of kibutz and non-kibutz children following death of the father. Journal of Children Psychology and Psychiatry and Allied Disciplines, v. 3, n. 24, p. 435-42, 1983.

Karam, George (1991). Post Traumatic Stress Disorder. The Lebanon Wars. Beirute: Publicado pelo programa de desenvolvimento das Nações Unidas, Departamento de Serviços Humanitários, 1994. 
Manjoub, Abdelwahab (1989). Approche Psychosociale des traumatisms de guerre chez les enfants et adolescents palestiniens. Tunis (Tunísia): Alif, Les Editions de la Méditerranée, 1995.

Punamaki, R. L. Psychological Reactins fo Palestinian and Israeli Children to War and Violence, Children and War. Proceeding of Symposium at Siunto Baths, Baths, Finland, maio, 1983.

Political Violence and Menthal Health, Londres, v. IV, n. 7, p. 3-15, jun./1989.

Reinert, M. Alceste une métodologie d'analyse de données textuelles et une application. Bulletin de méthdologie sociologique, n. 26, p. 24-54, 1990.

Manuel d'utilisation du logical Alceste. Université de Toulouse-Le-Mirail, 1992.

TAP, Pierre. Identité individuelle et personalisation. Toulouse: Privat, 1981.

TAR Kovacs, Fadia Nassif. Les Rumeurs dans la Guerre du Liban. Paris: Edições do CNRS, 1997.

Tatossian, A. La notion d' événement. De la phénoménologie à la méthode "life-events". In: Guyoat, J. (org.). Evénement et psychopathologie. Lyon: SIMEP, 1989.

El trabajo analiza los impactos que una crisis social extrema puede tener sobre construcción de la identidad (idiosincrasia) y de las condiciones psíquicas de los ciudadanos. Se buscó identificar cuáles fueron los dinamismos psíquicos y sociales que tuvieron importancia para enfrentar el peligro, superar las crisis y al término de dos combates, reconstruir sus vidas. El Líbano fue elegido por haber sido el escenario de una guerra interétnica larga, en la cual el pueblo Druzo estuvo en el centro de las confrontaciones. Para conocer esta realidad fueron confeccionadas trece historias de vida. El análisis del material recogido muestra el papel de la memoria colectiva y del discurso étnico como propiciadores de la cohesión grupal. La idealización y las creencias a través de sus ideologías, sirvieron como garantía de sentido en la mediación de lo vivido catastrófico.

Palabras claves: Processos de identidad, conflictos étnicos, Líbano, Druzos

Le but de ce travail est d'analyser les impacts qu'une crise sociale extrême peuvent avoir sur la construction identitaire et sur les conditions psychiques des citoyens. Nous avons cherché à identifier les enjeux psychiques et sociaux mis en oeuvre pour faire face au danger, pour surmonter la crise et, à la suite des conflits, pour reconstituer leurs vies. Le Liban a été choisi pour avoir été le scénario d'une longue 


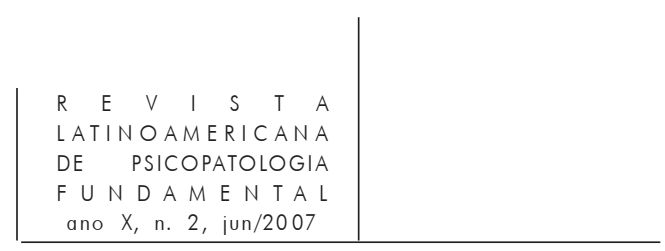

guerre inter-éthnique pendant laquelle le peuple Druze était au centre des ces conflits. Pour exploiter cette réalité, nous avons enregistré treize récits de vie. L'analyse du matériel récolté montre le rôle de la mémoire collective et du discours ethnique comme catalyseurs de la cohésion groupale. L'idéalisation et les croyances à travers leurs idéologies a servi comme étayage du sens dans la médiation du vécu catastrophique.

Mots clés: Processus identitaires, conflits ethniques, Liban, Druzes

This article discusses the impacts that an extreme social crisis on the construction of identity and the psychic conditions of the country's citizens. The author seeks to identify approriate psychic and social dynamics that will help persons face danger, overcome the crisis and restructure their lives after the combats are over. We focused on Lebanon because it has been the scene of a long inter-ethnic war where the Druses were the center of the confrontations. In order to become acquainted with reality we collected and analyzed thirteen life-stories. The analysis of this material showed that the role of collective memory and ethnic discourse is to promote group cohesion. It also showed that idealization and beliefs based on its ideologies guaranteed a sense of mediation of the the catastrophe they have gone through.

Key words: Identification processes, ethnic conflicts, Lebanon, Druses 